\title{
Mediation role of responsible innovation between CSR strategy and competitive advantage: Em- pirical evidence for the case of Saudi Arabia enterprises
}

\author{
Tarek Bel Hadj ${ }^{\mathrm{a}, \mathrm{b}^{*}}$, Anis Omri ${ }^{\mathrm{a}, \mathrm{c}}$ and Ahmad Al-Tit ${ }^{\mathrm{a}}$
}

${ }^{a}$ College of Business and Economics (CBE), Qassim University, Saudi Arabia

${ }^{b}$ Faculty of Economics and Management of Sousse, University of Sousse, Tunisia

${ }^{c}$ Faculty of Economics and Management of Nabeul, University of Carthage, Tunisia

C H R O N I C L E

\begin{tabular}{l} 
Article history: \\
Received: September 52019 \\
Received in revised format: Sep- \\
tember 82019 \\
Accepted: October 23, 2019 \\
Available online: \\
October 23, 2019 \\
\hline Keywords: \\
Corporate social responsibility \\
Reactive CSR \\
Strategic CSR \\
Responsible innovation \\
Competitive advantage
\end{tabular}

\begin{abstract}
This study examines whether responsible innovation can be an important channel through which the corporate social responsibility (CSR) strategy influences the competitive advantage of the firm. Specifically, we tried to test the role of firm size and activity sector as conditional factors in the mediation of responsible innovation between CSR strategy and the competitive advantage for the case of Saudi Arabia enterprises. Based on structural equation modelling (SEM), our results show that responsible innovation is a key element of the sustainable business model since it determines the success of CSR strategy in boosting the competitive advantage of firms. In this model, the mediation of responsible innovation is moderated differently by the firm size and the activity sector, and it is dependent on the choice between strategic or reactive CSR strategy. Within this context, we also find that the indirect effects of the CSR strategy on competitive advantage are moderated by the firm size in the case of reactive CSR, whereas by the activity sector in case of strategic CSR. The originality of this paper is that it examines whether the competitive advantage of firms in a developing country is more dependent on the reactive CSR strategy or the strategic CSR strategy. It also proposes an empirical investigation into the conditional factors of responsible innovation and their effects on the relationship between CSR strategy and competitive advantage.
\end{abstract}

\section{Introduction}

Over the last few years, studies on CSR including its environmental, social and economic issues constitute an interesting area of research. However, given the specificities of developing countries compared with the developed ones in terms of institutional framework, sources of economic growth, and lags in human development, it is not reasonable to transfer the arguments and conclusions of the research applied in developed countries to developing ones (Idemudia, 2011; Moon \& Shen, 2010; Jamali \& Karam, 2018). This is why the analysis of CSR in case of developing countries still remains a topic of research which has not yet sufficiently been explored. In this regard, attention was carefully attributed to the effects of CSR strategy on financial performance (Callan \& Thomas, 2009) through a set of mediating effects, such as reputation (Orlitzky et al., 2003), firm visibility (Martínez-Ferrero \& Frías-Aceituno, 2015; Hou, 2019), and stakeholders (Madsen \& Rodgers, 2015). Several studies have analyzed the mediating role of innovation in CSR-based competitiveness models. These mediating effects of innovation have been examined according to Resource-Based-View by Saeed and Archad (2012) who showed that the detention, creation and sharing of information as social capital exerts a mediating effect on the relationship between CSR and competitive advantage beside the reputational capital. Other researches have analyzed the joint mediating effects of innovation and those exerted by other variables in their models of CSR-based competitiveness. These include learning (Vilanova et al., 2009), productivity (Al-Shuhaibi, 2016), investment (Marin et al., 2017), and social capital (Zhao et al., 2019) as additional mediating variables besides innovation. Based on the previous literature that analyzed CSR-based competitiveness model, we found some gaps that we addressed in this paper, which can be summarized as follows: First, to the best of our knowledge, there is no research that empirically analyzed the conditional effects of CSR on competitive advantage through innovation in general, and responsible innovation in particular. Indeed, in the majority of previous studies that have focused on CSR-based

* Corresponding author

E-mail address: t.belhaj@qu.edu.sa (T. Bel Hadj) 
competitiveness, they have limited to analyze the mediating effect of innovation, not separately, but jointly with mediating effects of other variables (Al-Shuhaibi, 2016; Marin et al., 2017; Zhao et al., 2019). Second, a limited number of researches that have analyzed the effects of the CSR strategy, whether reactive or strategic, on the firm performance through the mediation of innovation (Bocquet et Mothe, 2010; Bocquet et al., 2017), and no research that empirically analyzed the moderating effects of the firm size and the activity sector in this mediation model. Third, although oriented towards developing countries, some other research studies on CSR-based competitiveness (Al-Shuaibi, 2016; Anser et al., 2018) have neglected important aspects specific to these countries. Indeed, since the CSR approach remains in its embryonic phase and lacks culture in the behavior of firms in developing countries, it is essential to distinguish between the CSR strategies that strengthen the competitiveness in these countries.

In light of these gaps, the current inquiry aims to analyze the role of reactive CSR and strategic CSR in determining competitive advantage by taking into account the mediating effects of responsible innovation. This is why we aim here to demonstrate how responsible innovation mediates the effects of reactive and strategic CSR on the competitive advantage of SMEs in the Saudi case. The central question of our paper is as such: Are the effects of strategic and reactive CSR on competitive advantage through responsible innovation conditioned by the firm size and the activity sector? Accordingly, the contributions of this study can be summarized as follows. First, we analyzed the conditional effects of CSR on the competitive advantage of enterprises through responsible innovation. These conditional effects stem from the moderating effects of the firm size and the activity sector. Second, we tried to show that the effects of firm size and activity sector in this moderated-mediation model differ according to the CSR strategy adopted by the firms. Third, although the firm size and the activity sector were retained in some research (Margolis \& Walsh, 2001; Siegel \& Vitaliano, 2007; Bocquet \& Mothe, 2010) as key factors in determining the effects of CSR on the competitiveness of firms, there is no empirical research that has focused on their conditional effects between strategic and reactive CSR and responsible innovation. To this end, we propose an empirical study analyzing the moderating effects of firm size and activity sector in the relationship between strategic and reactive CSR and responsible innovation. Finally, we chose to validate this model in the case of an emerging country such as Saudi Arabia. In this regard, one of the developing countries that deserve to be analyzed in terms of socially responsible business is Saudi Arabia. The success of the CSR model in Saudi Arabia can have repercussions on its policies of the choice of renewable energy as a substitute for the fossil energy, the production of green innovation as a new lever for economic growth, and the development of human welfare. This is especially important since Saudi Arabia, according to the Organization of the Petroleum Exporting Countries (OPEC), holds $18 \%$ of the proven oil reserves and is ranked as the world's leading producer and exporter of oil. In addition, $50 \%$ of GDP and $70 \%$ of exports come from the oil and gas sector. In fact, Saudi Arabia has set new challenges under the vision 2030 in terms of diversification of sources of economic growth and new trends in social welfare and the environment management. To this end, Arabian General Investment Authority has set a number of priorities for the creation of integrated sites that aim to diversify the economic fabric, the absorption of unemployment by creating more than one million jobs, the encouragement of private-public partnership while preserving the environment, and encouraging energy saving and sustainability. However, despite these attempts, according to the report of the World Economic Forum in 2018, Saudi Arabia is ranked $39^{\text {th }}$ among the most competitive nation in the world, the gap is widening on a world scale. In addition, Saudi Arabia has $90 \%$ of SMEs, creating $60 \%$ of the total employment, which reflects the role played by this type of enterprises as the main animator of the economic activity. The predominance of SMEs compared to the larger firms may have significant effects on the practice of CSR in Saudi Arabia. Indeed, these SMEs are less concerned with socially responsible business and their sustainability, and more interested to their survival on the market. Therefore, it is interesting to make the CSR policy as a strategic approach for these companies and not only under the pressures exerted by the different stakeholders.

This paper is structured as follows: First, we exposed the literature on the relationship between the CSR strategy and the competitive advantage, the mediation role of responsible innovation, as well as the conditional effects of the firm size and the activity sector in this relationship. Then, we explained our research methodology followed by a presentation and a discussion of the results. Finally, we have proposed a set of theoretical, practical, policy implications and limitation of the paper.

\section{Literature review and hypotheses development}

\subsection{CSR strategy and competitive advantage}

Most of prior research that focused on responsible innovation have shown that a socially responsible or "sustainability-oriented" innovation creates additional environmental and social value-added, along with increased competitive advantage of companies (Halme \& Korpela, 2014). In this regard, environmental and social dimensions must be considered in the production and development of new products and processes (Adams et al., 2016, Boons et al., 2013; Klewitz \& Hansen, 2014). In fact, responsible innovation has been described by McGregor and Fontrodona (2007) as "sustainable design", which deals with how designers take environmental and social concerns into account in order to propose innovative solutions. For many actors (business leaders, policy-makers, professional unions), the CSR is no longer perceived merely as a constraint, but also as an opportunity for social cohesion and competitiveness of companies. From an economic point of view, CSR is seen as a balanced way of managing wealth, but, also risks by taking into account the interests of all stakeholders (employees, customers, suppliers, local authorities, consumers etc.). Indeed, many studies have shown that responsible innovation allows real gains for companies: Higher prices for green products or services, image gains, cost reductions linked to better use of resources 
(Porter and van der Linde, 1995; Shrivastava, 1995; Henriques \& Sadorsky, 1999), and the improvement of the quality of products and services. However, the effect of CSR on the competitive advantage must take into account the reactive or strategic nature of CSR practices. According to the reactive approach, sustainable development was perceived as a constraint, triggered by pressure from public opinion and governments (Nidumolu et al., 2009). They are, therefore, far removed from business concerns (Porter \& Kramer, 2006). In this case, integrating the firm into a sustainable development approach is aligned with the current "Business Ethics", which emphasizes the moral necessity for the company to carry out its activities in a socially responsible manner. Moreover, many studies show that sustainable development and competitiveness of companies are not antinomic. This idea is justified by the measures that make it possible to achieve savings in terms of energy costs or resources or to respond to market opportunities while contributing to the preservation of the environment. In this case, the responsible innovation is a response to the strategic approach. This approach generally involves the theory of resources and competences, developed in particular by Wernfelt (1984) and Hamel and Prahalad (1990), or "dynamic capacities" (Teece et al., 1997). Moreover, neoclassical approaches have postulated that responsible innovation is justified by the search for profit (Capron \& Quairel-Lanoizelée, 2007). The alignment between CSR, responsible innovation and competitiveness, therefore, appears relevant and meaningful.

The two strategic and reactive approaches which interpose in the relationship between responsible innovation and competitive advantage can be reconciled around one common point which is the role of resources. Hart (1995) noted that one of the key capabilities of firms, in a perspective of competitive advantage, lies in its resources to deal with the environmental issue. This is what he calls a natural-resource-view of the firm. According to the Resource-Based-View (RBV), which assigns resources a driving role in the creation of the competitive advantage of firms, the competitive position of a company dependent on its reputation on the market (Lai et al., 2010). Indeed, this reputation encourages the positive reactions of the various stakeholders in their decision-making processes: The attractiveness of skills from the job market, the encouragement of investors to invest, and the motivation of consumer demand for goods and services (Maden et al., 2012). In this respect, the business sustainability is explained by a good image thanks to a positive attitude and a greater attachment of the consumers, which further strengthens the reputation of the company (Hur et al., 2014). However, this reputation may be unclear and does not reflect the specific characteristics of the products and services produced by the company or the nature of its activity. The literature qualifies this action by CSR washing. To this end, the neo-institutional theory considers that if companies profit more from CSR practices they must proceed to limit consumer skepticism regarding CSR claims (Brammer \& Pavelin, 2006; Pomering \& Donicar, 2009) and seemingly high performance in responsible actions (Barnett and Solomon 2006). This approach makes it possible to take into account the expectations of different stakeholders, in particular through a good management of the products, throughout their life cycle, which can boost the competitive position of the firm in the market. This contribution is clearly in the environmental field, from a strategic perspective. More recently, a set of francophone researches (e.g. Brion et al., 2008; Depret \& Hamdouch, 2009) has exploited data from surveys carried out in Luxembourg companies to identify the relationship between responsible innovation and competitiveness based on CSR. In particular, the realization of radical or incremental innovations, but not organizational, has a positive impact on the propensity to implement CSR approaches. They interpret these observations by considering that the CSR behavior of the company can be assimilated to an investment in a social technology whose adoption should have a positive impact on the performance of the firm, as well as, in complementary with the" technological innovation.

For their side, Bocquet and Mothe (2010) have sought to determine whether commitment to CSR can lead to technological innovation. They find that companies engaged in reactive CSR approaches mainly develop incremental innovations, whereas those that have opted for strategic CSR implement more radical technological innovations, regardless of the size of the company. In addition, the CSR voluntary criterion reflects strategic thinking among companies wishing to integrate social and / or environmental concerns at the heart of their strategy. Opening up to social and environmental issues inscribes the company in a broad consideration of its stakeholders (Aggeri \& Godard, 2006) and assigns it a responsibility towards the actors with whom it interacts, directly or indirectly. Bocquet and Mothe (2010) interpreted this result by considering that when CSR is strategic for the company, relationships with stakeholders are more numerous, whereas when it is only reactive, companies concentrate their stakeholders, including internal stakeholders, employees and then customers. Moreover, Porter and Kramer (2006) also analyzed the relationship between CSR and competitiveness based on the strategy of CSR. On the one hand, the reactive CSR strategy aims to respond to the various pressures exerted by the company's stakeholders. On the other, strategic CSR adoption, which goes beyond the implementation of good practices (and compliance with legislation, especially in the social field) and requires coordination between CSR practices and business strategy which creates a virtuous circle for innovation activities to develop. Burke and Logsdon (1996) have transposed the strategic approach in terms of CSR, arguing that engagement in social, societal and / or environmental actions create opportunities for value creation. The analytical framework developed makes it possible to establish a strong relationship between strategic CSR, responsible innovation and competitive advantage. Indeed, as pointed out by Husted and Allen (2007,p. 597), "value creation is necessarily related to innovation". Value creation occurs not only when consumers agree to pay more for socially responsible products, but also because of the economic manner in which resources are used, thereby increasing their efficiency. A third approach, which focused on the analysis of the relationship between responsible innovation and CSR, is that which avoids confusion between strategic and reactive approaches. McGregor and Fontrodona (2008), in an exploratory study aimed at identifying ways to integrate CSR into the current management of SMEs, postulated, first of all, that the commitment of companies in CSR can be represented as a process of innovation diffusion, in accordance with the model of Rogers (1962), and based on a typology of adoption 
behaviors over time. Second, the authors propose a model of a virtuous circle between responsible innovation and CSR: Responsible innovation can be oriented towards CSR when it is motivated by values and ends up with products and services with a social vocation, "good things". In this case, socially responsible efforts are at the level of the process in favor of, for example, employees or suppliers. On the contrary, CSR can be innovation-oriented when justified by the search for value creation. This bi-directional model thus, takes into account the CSR-responsible innovation relationship in both directions, even if the modalities of this virtuous circle are not really explicit except for the empirical research of Mc Gregor and Fontrodona (2008), Gallego Alvarez et al. (2011), other research focused on unidirectional relationships between CSR and innovation. At this level, according to Mc Gregor and Fontrodona (2008), the creation of responsible innovation is stimulated by search for value, in accordance with the strategic approach, or driven by value, in accordance with the reactive approach. In contrast, the vision of Gallego Alvarez et al. (2011) differs since the effects of CSR on innovation are rather negative due to the costs generated by the decrease in the stock value. Moreover, the majority of empirical research that has analyzed the relationship between CSR and innovation is based either on responsible innovation (Mc Gregor and Fontrodona, 2008, Wagner 2010, Bocken et al, 2014), or on product and / or process innovation (Husted \& Allen, 2007, Bocquet et al., 2013; Bocquet et al., 2017; Marin et al., 2017) without identifying the mechanisms that condition the mediation of responsible innovation between CSR and competitive advantage. Wondering about the respect of international standards in terms of certifications, some authors (Su et al., 2016; Boirel et al., 2017; Iatridis \& Kesidou, 2018) have shown that the pressure exerted by stakeholders, namely public authorities, buyers, suppliers, shareholders and financial institutions, is not expected to have a significant and positive effect on the substantive practice of these standards. Certifications obtained are only a means of disguising reality, especially towards the financial market, which reduces the risk of damage to the reputation, even if these practices are intrinsically integrated.

\subsection{CSR and competitive advantage: The mediation role of responsible innovation}

In the following, we justify this relationship between CSR and competitive advantage by showing that the effects of responsible innovation are mediated differently by the strategic or reactive approach of the CSR while taking into consideration the conditional effects of the size of the company and the sector activity. We consider that such an approach is original since the literature on the theme of responsible innovation-based-competitiveness refers only to the mediating effects without integrating the moderating effects involved in this relationship. In other words, the contribution of our research lies in the proposal of a detailed study of the moderated mediation role of responsible innovation in the relationship between CSR strategy and competitive advantage. Among the research that has proposed a model of CSR-based competitiveness is that of Vilanova et al. (2009) who showed that the CSR strategy and the competitive advantage of firms are mediated through the learning and innovation cycle and by emphasizing the values of the manager, the strategy, and the actions that need to be continuously updated. For their part, based on Resources-Based View, Saeed and Archad (2012) analyzed the effects of the CSR on competitive advantage and showed that the intangible organizational resource can be achieved by engaging in CSR activities, but this is only possible through the mediation of reputational capital and social capital. To this end, they have shown that social capital in the form of detention and the creation of technological information, and the sharing of knowledge are important tools in business success. For their side, Hull and Rothenberg (2008) pointed out that the effects of CSR on firm performance is moderated by innovation and the level of differentiation in the industry. Later, the results of Marin et al. (2017) on a sample of 236 firms showed that there are no direct effects of CSR on competitiveness, but require a mediation of innovation and investment. However, the models proposed in this literature are theoretical and need empirical validation (Vilanova et al., 2009; Saeed and Archad;2012) and they did not try to test their validity in developing countries. In the context of developing countries, there is little research on the channels through which CSR can influence the competitive advantage of firms. Based on a sample of 197 Saudi firms, Al Shuaidi (2016) used a structural equation modeling and his results showed that the effects of the CSR on the firm's performance are mediated by innovation and productivity. In fact, the analysis of the role of the CSR strategy in stimulating responsible innovation differs between strategic and reactive CSR. Concerning the reactive approach, responsible innovation through CSR is a response to the requirements of the different stakeholders. Indeed, the notion of CSR has contributed to the emergence of environmental management, highlighting the responsibility of companies, not only with internal stakeholders, but also with its external environment. If the company is accountable for its economic results, it must also report on its behavior, whether social or environmental (Capron and Quairel, 2007). Beyond legal and economic obligations, CSR implies that the company must approach a set of stakeholders, thus placing it at the heart of relationships with partners who are no longer just its shareholders. As Van den Berghe and Louche (2005) pointed out, "companies are faced with a new invisible hand, dictated by the non-market forces exerted by NGOs, media, trade unions and others, and under the impact of this new invisible hand they are beginning to see CSR as a prerequisite for sustainable welfare and growth". The literature also highlighted the role of key resources in the emergence of sustainable technologies (Hart, 1995), and identified the benefits of responsible innovation (Porter and van der Linde 1995, Shrivastava 1995, Chen et al., 2009). At the level of these inter-organizational relationships, empirical research has mainly been carried out on vertical relationships (customers, suppliers) and horizontal relationships (competitors). Thus, Simpson and Kohers (2002) and De Marchi (2012) highlighted the importance of partnerships with suppliers in the development of technological environmental innovations. More recently, according to Dorobantu et al. (2017), CSR represents not just a way to do good, but is mainly a strategy through which firm respond to a new set of local institutions, with the expectations that they will be rewarded for such activities by stakeholders. As a result, companies produce responsible innovation in order to meet the requirements of these different stakeholders, including employees, customers, suppliers and shareholders. Moreover, Porter and Van Der Linde (1995) considered environmental regulations as a factor encouraging competitiveness in a "win-win" approach, in particular because responsible 
innovation requires cooperation with other actors. In some cases, CSR can save transaction costs associated with regulatory processes or even constitute a private response to regulatory failures. CSR replaces regulations when it prompts them, that is, when it avoids future stronger regulatory constraints. In this regards, Lutz et al. (2000) showed that if companies can commit themselves to a quality standard and invest slightly more before they are promulgated, the regulator is generally pressured to weaken its requirements in order to limit the costs it would impose on firms, which are more virtuous. Beyond this theory of mutual reinforcement, CSR can also be complementary to regulations when governments fail, for multiple reasons (Bénabou and Tirole, 2010): (i) Capture by lobbies and other interests; (ii) territoriality of jurisdictions (as for child labor, for example); (iii) a cross between inefficiencies, (iv) high transaction costs, and (v) low information and high delivery costs. For example, the regulator may wish to reduce the cost of regulatory implementation (especially transaction costs) and therefore, rely on voluntary agreements (Lyon and Maxwell, 2008). In the light of the above discussion, strategic and reactive CSR create a competitive advantage for firms, but the mechanisms by which these effects are transmitted differ. For the reactive CSR, the creation of a competitive advantage is rather facilitated by a stakeholder push, whereas for the strategic CSR, this competitive advantage is justified by a market pull. Thus, we try to validate the following central hypothesis:

Hypothesis 1: Responsible innovation has a mediating effect on the relationship between the CSR strategy and the competitive advantage.

We then decompose Hypothesis $\mathrm{H}_{1}$ into two sub-hypotheses:

$\mathrm{H}_{1 \mathrm{a}}$ : Reactive CSR is positively associated with the competitive advantage via responsible innovation.

$\mathrm{H}_{1 \mathrm{~b}}$ : Strategic CSR is positively associated with competitive advantage via responsible innovation.

\subsection{CSR and responsible innovation: The moderating role of the firm size and activity sector}

\subsubsection{Firm size, CSR and responsible innovation}

Since our research concerns both SMEs and large companies, it is interesting to analyze how the size of the company affects differently the responsible innovation. Different factors favor the adoption of CSR practices, including the manager and his strategic profile in small businesses (Paradas, 2005; Berger-Douce, 2007), customer pressure (Quairel \& Auberger, 2005), and belonging to a typical network or a grouping of SMEs (Bonneveux \& Saulquin, 2009). From seven case studies of French companies, Bocquet and Mothe (2010) analyze the relationship between CSR and responsible innovation according to the firm size. According to these authors, CSR in SMEs is strongly embedded in the values of the manager, which allows him to carry out radical innovations by combining the strategic dimension with an informal approach. Although SMEs are less likely than large ones to become involved in CSR approaches, many SMEs consider this approach as an important source of competitive advantage. CSR practices enable SMEs to easily access to customers, to explore new markets, and to facilitate their acceptance by the society. Moreover, the orientation towards responsible innovation is not only explained by the small size of the firms. Indeed, social pressure appears as a major determinant of CSR for large firms, which are consumer-oriented and well-known companies and therefore, they are committed to preserve their "license to operate". The results of Bocquet and Mothe (2010) showed, therefore, that responsible innovation seems justified by a strategic approach for SMEs and a reactive and preventive approach for large firms. In addition, the measures used to characterize sustainable development on the one hand (with the use of indexes), and innovation (mainly R \& D) on the other, remain to be improved. Indeed, they are not well suited to SMEs that do not always have directly observable CSR practices or formal R \& D activities to innovate. Otherwise, sustainability can first be promoted by SMEs. Indeed, large companies consider that the climate crisis must be tackled not only for ecological reasons, but also and above all to avoid harming their business in the long term. According to Geels (2014), large firms are not adopting new sustainable business models, but are still ingrained in their habits, what is called "regime resistance". This result is confirmed by Wüstenhagen and Boehnke (2008) who showed that barriers to enhanced offerings which characterize large companies are often found in supply chain dependencies and locked-in infrastructure. Furthermore, shareholders want to get the most out of their investments, but the expectation of returns on investments from responsible innovation can often be long. So as not to upset their shareholders, companies decide not to adopt this type of innovation. There are a number of reasons why large companies are reluctant to change, leading to a voluntary resistance to responsible innovation and, more generally, to the sustainability of the economy. Therefore, small companies that do not operate in shareholding, can act as a leader in the field of responsible innovation and subsequently motivate large companies to take the initiative to ensure sustainability. In the light of the above ideas, we propose the following second hypothesis:

Hypothesis 2: The indirect effect of the CSR strategy on competitive advantage is moderated by the firm size.

This second hypothesis is tested by decomposing it into two sub-hypotheses:

$\mathrm{H}_{2 \mathrm{a}}$ : The indirect effect of the reactive CSR on competitive advantage is moderated by the firm size.

$\mathrm{H}_{2 \mathrm{~b}}$ : The indirect effect of the strategic CSR on competitive advantage is moderated by the firm size.

\subsubsection{Activity sector, CSR and responsible innovation}

The activity sector appears to have an influence on the relationship between responsible innovation and competitive advantage. The sectoral factor illustrates the influence of professional culture on CSR. The relationship is here studied in the 
direction of CSR towards technological innovation. In fact, the expression green growth is sometimes used with the idea that there are opportunities for economic growth in sectors related to the preservation of the environment. However, there is no rational justification for these sectors to be more likely than others to stimulate innovations that generate economic growth. Moreover, CSR is primarily the implementation of sustainable development by companies, and it calls for a long-term vision, oriented towards externalities, which cannot be confused with the notion of competitive advantage if the latter gives primacy to profitability. In this sense, the sector of activity is considered due to the need to take into account the degree of impact of responsible innovation on sustainable development in general, and the social and human environment and therefore, the exposure to the vigilance of external stakeholders in particular. This factor, is therefore, relevant for identifying potential gains from a strategy integrating CSR. To this end, it is mainly in the energy and environment sectors that CSR is the most widely disseminated whereas other sectors, such as trade or the automobile, are less widespread. The role of sectoral ownership in the creation of responsible innovation was analyzed by the theory of social and environmental contestability. According to this theory, for an economic activity to be questioned, it must come from innovative firms or from sectors that are notoriously controversial and represent significant players in their market. The relationship between the firm's visibility in its market and the level of CSR has been demonstrated in numerous empirical studies (Martínez-Ferrero and Frías-Aceituno, 2015; and Hou, 2018). In this regards, CSR can represent a strategic approach to prevent social and environmental contestability and to protect the long-term interests of the company. However, not all questionable firms become targets for activists. Visibility increases, in particular with public exposure as in consumer industries (Margolis and Walsh, 2001) or in controversial industries (Brown et al., 2006). From their side, Siegel and Vitaliano (2007) showed that firms, which sell "experience goods" or "trusted goods" are more likely to be socially and environmentally responsible than firms that sell "research goods". Despite the contradiction between the theoretical acceptance of sustainability and inertia in the face of change, some companies are still trying to make incremental changes in their activities. The automotive sector illustrates this phenomenon very well (Geels et al., 2015). The commitment of this sector to sustainable products remains limited, because if electric or hybrid cars are excellent as sustainable products, sales figures do not explode. The market for green cars, is therefore, too small to upset the commercial strategy of car manufacturers. Based on this discussion, we propose the following hypothesis:

Hypothesis 3: The indirect effect of the CSR strategy on competitive advantage is conditioned by the activity sector of the firm.

This last hypothesis H3 is tested by decomposing it into two sub-hypotheses:

$\mathrm{H}_{3 \mathrm{a}}$ : The indirect effect of the reactive CSR on competitive advantage is conditioned by the activity sector of the firm. $\mathrm{H}_{3 \mathrm{~b}}$ : The indirect effect of the strategic CSR on competitive advantage is conditioned by the activity sector of the firm.

Overall, the relationship between CSR strategy, responsible innovation and competitive advantage can be shown by Fig. 1.

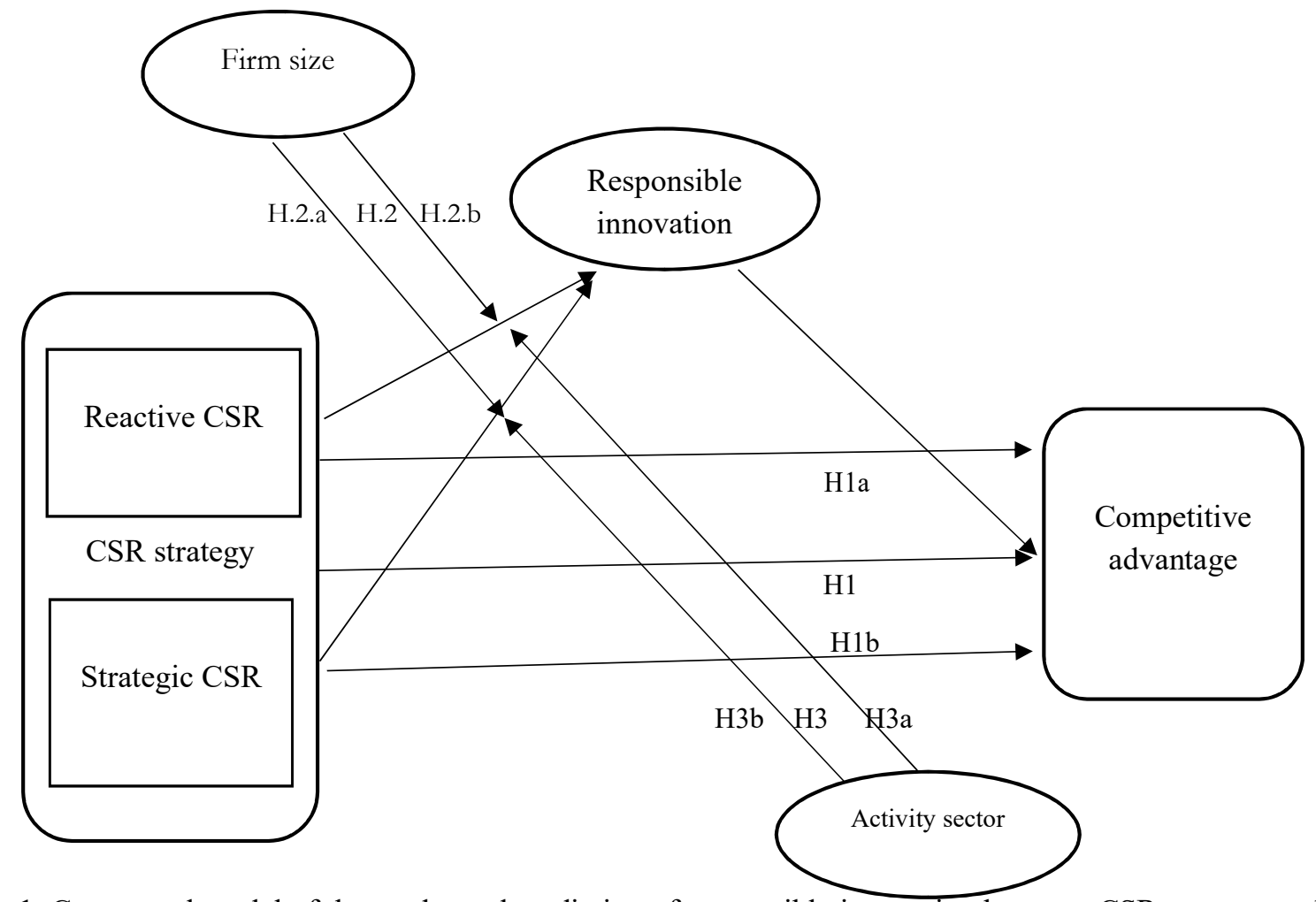

Fig. 1. Conceptual model of the moderated mediation of responsible innovation between CSR strategy and competitive advantage 


\section{Methodology}

\subsection{Data collection}

Our data were collected through a questionnaire addressed electronically to the Saudi companies. The population of our research is composed of 165 Saudi firms. Following the receipt of the data, it turned out that some forms contained outliers or missing data. That is why we filtered the answers collected and chose to eliminate some companies. In total, out of a population of 165 Saudi companies, we relied on a sample of 108 firms. Given that our questionnaire contains confidential information specific to companies including the strategy adopted in the CSR approach and responsible innovation policy, we have guaranteed anonymity for all respondents of our sample. Our data were processed using the SPSS 23.0 software to empirically analyze the moderated mediation of responsible innovation in the relationship between CSR strategy and the competitive advantage. We rely on the structural equations model to conduct our estimates.

\subsection{Sample selection}

Insofar, as our research integrates both large and small and medium enterprises, we have selected 3 groups of companies based on the number of employees. We rely on the number of employees rather than other indicators (capital assets, turnover and legal status) to measure the firm size. We have retained the definition of the Saudi Arabian General Investment Authority, according to which the very small business in Saudi Arabia are those employing less than 60 employees, medium-sized enterprises having fewer than 100 employees, firms with more than 100 employees are considered as large firms. In order to avoid selection bias, we selected different sectors. Indeed, these firms belong to the sectors of the energy, manufacturing, chemical products, metallurgical products, construction products, and services. This choice is further justified by the fact that the CSR strategy and responsible innovation differ according to the sector in question. Some sectors are more polluting, others less polluting. Moreover, this choice makes it possible to distinguish between high and medium technology sectors with high potential for innovation against low technological sectors and therefore, less innovative. Respondents to the questionnaire are mainly large firms that make up $82.4 \%$ of our sample followed by very small enterprises and small and medium-sized enterprises with shares of $10.2 \%$ and $7.4 \%$ of the total sample, respectively. The analysis of the responses received shows that these companies are mainly active in the sectors of manufacturing products and Agri-food with shares of $49 \%$ and $32.4 \%$ of the total sample, respectively. The rest of the companies is active in energy, construction products, metallurgical products, and chemical products which represent $7.4 \%, 6.5 \%, 3.7 \%$, and $1 \%$, respectively.

\subsection{Measuring variables}

In our research, we distinguish between two types of CSR strategy: Strategic CSR and reactive CSR. In what follows, we explain the approaches adopted to measure the variables related to the strategic CSR, reactive CSR, responsible innovation, and competitive advantage.

\section{- $\quad$ Strategic CSR}

In order to measure strategic CSR, we followed the approach of Husted and Allen (2007), which included five criteria: visibility, appropriability, voluntarism, centrality and pro-activity. In our research these criteria are respectively formulated by the following items: "Have you sensitize customers and stakeholders about products with CSR value?"; "Do you manage stakeholder relationships to add value to the firm?"; "Have you participate in social actions going beyond what the law imposes?"; "Have you created value through the product / service innovation for social purpose?"; "Are you able to anticipate social changes that present market opportunities?".

\section{- $\quad$ Reactive CSR}

With regard to the reactive CSR, we focused on the reactivity of firms to the stakeholder requirements. In our research, reactive CSR is measured by the degree of influence of the internal and external stakeholders of the firm, as was shown by Porter and Kramer (2006). We retained the pressures exerted by employees, consumers, suppliers, the government, and the shareholders in the implementation of CSR policy by the firm. The degree of influence can vary on a 5-point scale from "no influence" to "very strong influence".

\section{- Responsible innovation}

In our research, responsible innovation as a mediating variable is measured by its 4 main components taken from the analysis of Stilgoe et al. (2013), namely: Inclusion, anticipation, responsiveness and reflexivity. These components reflect respectively "the participation of different stakeholders in the innovation process", "the integration of current social and environmental trends in terms of innovation in the design of the future", "the ability of the firm to identify and react to potential risks", and "the ability of the firm to design its products in accordance with the culture and traditions of the society to which it belongs". To do this, we based on a 4-point Likert scale ranging from "not at all" to "always". 
In order to measure the competitive advantage, we followed Sigalas et al. (2013) by focusing on 3 main indicators, namely: Exploitation of market opportunities; neutralization of threats and reduction of total costs. This method seems to us to be adequate as it provides a clear and an operational measure of competitive advantage that could increase the awareness of practicing executives of the conceptual nature and latent expressions of competitive advantage. The exploitation of opportunities can take 3 different configurations. 1) Exploitation of all market opportunities; 2) Full exploitation of market opportunities; and 3) More exploitation of market opportunities compared to its competitors. The neutralization of threats also takes three possibilities: 1) Neutralizing all threats present on the market or; 2) Completely neutralizing the competitive threats of the market or; 3) Neutralizing threats more effectively than its competitors. Finally, cost reduction is assessed in four ways: 1) Reducing total expenses more effectively than competitors; 2) Reducing operating expenses more effectively compared to competitors; 3) More noticeable reduction in total expenses divided by revenue compared to competitors and; 4) a much sharper reduction in operating expenses divided by revenue in comparison with its competitors. Each item of the competitive advantage is measured by a scale of five- point Likert.

\subsection{Model to estimate}

In our research on mediation, we focus on estimating the indirect effect of the CSR strategy on competitive advantage by using the mediating variable responsible innovation causally located between these two variables. According to Hayes (2015), the general form of the first stage moderated mediation model is written by the following two equations:

$$
\begin{aligned}
& M=i_{M}+a X+e_{M} \\
& Y=i_{Y}+c^{\prime} X+b M+e_{Y}
\end{aligned}
$$

where $\mathrm{a}, \mathrm{b}$, and $\mathrm{c}$ are estimated regression coefficients, $i_{M}$ and $i_{Y}$ are regression intercepts, and $e_{M}$ and $e_{Y}$ are errors in estimation. The product of $\mathrm{a}$ and $\mathrm{b}$ measures the indirect effect of $X$ on $Y$. By transposing these equations in our specific case of moderated mediation in which the indirect effect of the CSR strategy (csr) on competitive advantage (ca) by responsible innovation ( $r i$ ) can be obtained using two linear models. The first equation describing the effect of the CSR strategy ( $c s r$ ) on responsible innovation (ri) is formulated as follows:

$$
r i=i_{r i}+a \operatorname{csr}+e_{r i}
$$

In the second equation, the variable $c a$ is estimated in linear function of $r i$ and $c s r$. Our conceptual model represented by Figure 1 requires, in accordance with the approach of Hayes (2015), two equations to estimate the indirect effect of CSR strategy on competitive advantage. In the first equation, the variable ri is estimated in the form of a linear function of csr, with the effect of csr on $r i$ being modeled in a linear function of the moderating variable $W$. This is why equation 1 is reformulated by equation 2 . So, the moderated mediation model is described by both equations 2 and 3 as follows:

$$
\begin{aligned}
& r i=i_{r i}+a_{1} c s r+a_{2} W+a_{3} W c s r+e_{r i} \\
& c a=i_{c a}+c^{\prime} c s r+b r i+e_{c a}
\end{aligned}
$$

Eq. (3) is a model of moderation (Edwards and Lambert, 2007) that takes into account the effect of $c s r$ on $r i$ in a mediation model called by Fairchild and MacKinnon (2009) as an action theory. The statistical model derived from the conceptual model illustrated in Fig. 1 is therefore, represented by Fig. 2 as follows:

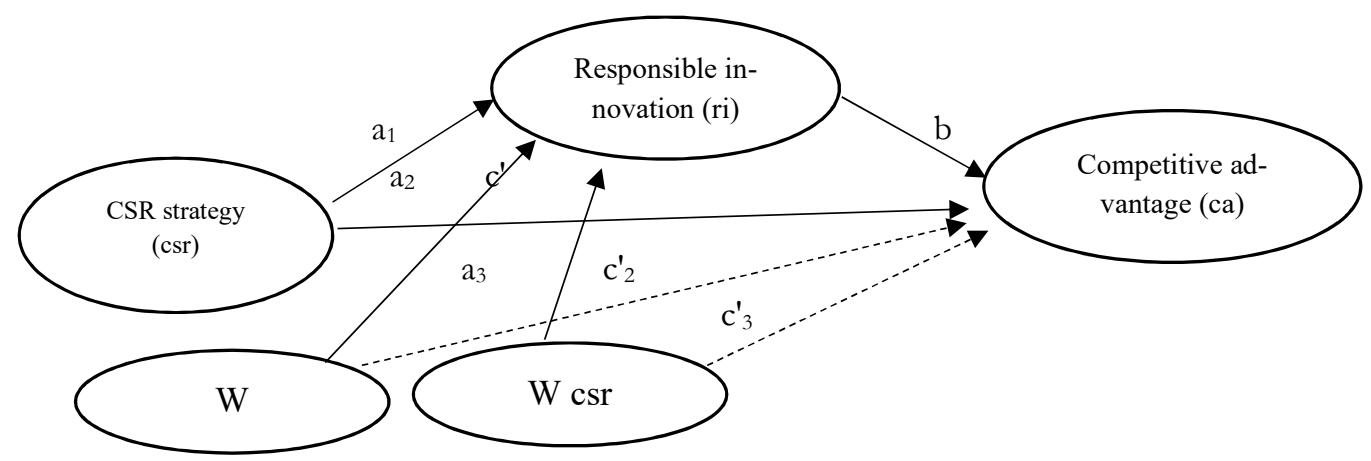

Fig. 2. Statistical model of the moderated mediation of responsible innovation between CSR strategy and competitive advantage 
Fig. 2 described the first stage and direct effect moderation model described by Edwards and Lambert (2007), or "Model 2" in Preacher et al. (2007). The indirect effect of $c s r$ on $c a$ through the mediating variable ri ( $\omega$ in the notation below) is the product of the conditional effect of $c s r$ on $r i$ of the Eq. (3) and the effect of $r i$ on $c a$ by controlling $c s r$ in Eq. (2).

$$
w=\left(a_{1}+a_{3} W\right) b
$$

Eq. (4) can be reformulated by equation 5 as follow:

$$
w=a_{1} b+a_{3} b W
$$

In this last equation, $\mathrm{a} 1 \mathrm{~b}$ and $\mathrm{a} 3 \mathrm{~b}$ respectively designate the intercept and the slope. According to Morgan-Lopez and MacKinnon (2006), a3b measures the contribution of a moderating variable ( $W$ in our model) in determining the indirect effect of an independent variable (csr in our model) on a dependent variable ( $c$ a in our model) through a mediating variable ( $r$ in our model) and it is qualified by Hayes (2015) as the index of moderated mediation for this model. In our model, the moderating variables noted by $W$ are the firm size and the activity sector. In other words, the indirect effect of CSR strategy on the competitive advantage through responsible innovation is a function defined as the product of the conditional effect of CSR strategy and responsible innovation by integrating the moderating effect of the size of the company and the activity sector, and the effect of the responsible innovation on the competitive advantage by controlling the CSR strategy. The analysis of moderated mediation is done on two types of models according to the CSR strategy: reactive CSR model and strategic CSR model.

\section{Results and discussion}

Our analysis of the conditional effects of responsible innovation as a mediating variable between CSR strategy and competitive advantage is carried out in two stages. In the first stage, we conduct an exploratory and confirmatory factor analysis to verify the consistency, the reliability and the validity of the chosen items. In the second stage, we will attempt to answer the central questions raised by our axial hypotheses based on the estimates of the models 2 and 3 , and also, to derive the value of the index of moderated mediation formulated by model 5 following the approach of Hayes (2015). In order to overcome the problem of the common method variance, we used the Harmann Single-factor test. To do this, we applied a Principal Component Analysis (PCA) by loading the 26 items used in our research on a single factor. For this purpose, the factor analysis shows that $33 \%$ of variance was extracted which is below the conventionally tolerated threshold that is equal to $50 \%$.

\section{Table 1}

Constructs and measures.

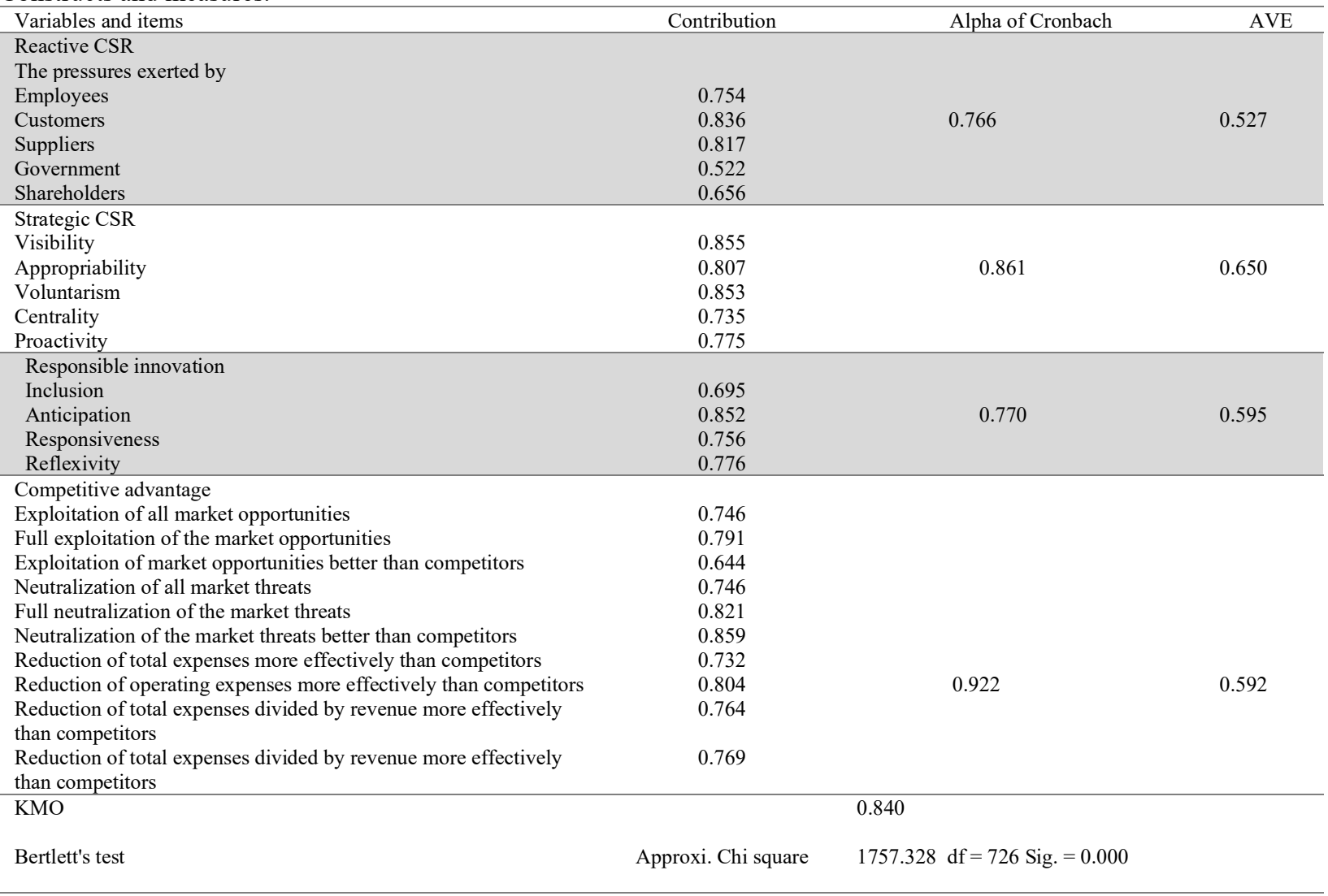


These results reflect that in the data set, the problem of the common method variance does not arise. To ensure convergent and discriminant validity and thus, the quality of the instruments, we conducted a PCA on the dimensions of the 26 items selected in our research. To verify the validity of the constructions and the adequacy of the sampling of the individual variables, we used the Bartlett's test of Sphericity and the Kaiser Mayer Olkin test (KMO). In this regard, the results in the Table 1 show that the KMO is greater than 0.6 and therefore, in accordance with Ozdamar (2002), it is significant as well as for the Bartlett's test of Sphericity. These results, therefore, allow a factor analysis. The table 1 shows also that the factor contributions of all items exceed 0.5 and therefore, according to Hair et al. (1998), they are all retained. It appears that measures of key variables in our research have acceptable convergent validity. Moreover, the total scales of reliability measured by Cronbach alpha for the 4 key variables of our research range from 0.766 to 0.922 which exceed the reliability threshold of 0.7 fixed by Nunnally (1978) and reflect the reliability of the measures of the selected items. In addition, average variance extracted (AVE) as an additional indicator of convergent and discriminant validity are greater than the threshold of 0.5 . Indeed, for the variable related to reactive CSR, strategic CSR, responsible innovation, and competitive advantage, AVE are between 0.527 and 0.650 which shows that the selected items have satisfactory levels for accepting convergent and discriminating validity. Figure 3 presented in detail the different items and correlations between the key variables retained in our research. The results of the Pearson's correlation shown by Table 2 show positive and significant coefficients between the CSR strategy, whether reactive or strategic, with responsible innovation and competitive advantage. In addition, our results illustrate that responsible innovation and competitive advantage are positively and significantly correlated. These results allow us to predict, a priori, a possible mediation of responsible innovation between CSR strategy and competitive advantage. Table 2 reported Pearson's correlation and summary statistics that include the minimum, maximum, standard deviation, mean and median of the main variables of our research.

\section{Table 2}

Pearson's correlation and summary statistics.

\begin{tabular}{|c|c|c|c|c|}
\hline Variables & Reactive CSR & Strategic CSR & $\begin{array}{l}\text { Responsible inno- } \\
\text { vation }\end{array}$ & Competitive advantage \\
\hline Reactive CSR & 1 & & & \\
\hline Strategic CSR & $0.225^{* *}$ & 1 & & \\
\hline Responsible innovation & $0.374 * * *$ & $0.477 * *$ & 1 & 1 \\
\hline Competitive advantage & $0.201 * *$ & $0.607 * * *$ & $0.592 * * *$ & 108 \\
\hline $\mathrm{N}$ & 108 & 108 & 108 & 20.101 \\
\hline Mean & 8.193 & 11.121 & 7.868 & 5.540 \\
\hline SD & 2.767 & 3.405 & 2.394 & 30.704 \\
\hline Max & 14.560 & 16.100 & 11.621 & 2.928 \\
\hline Min & 0.548 & 0.775 & 0.756 & 20.725 \\
\hline Median & 8.247 & 12.075 & 8.471 & \\
\hline
\end{tabular}

Notes: $* * * \mathrm{p}<0.01 ; * * \mathrm{p}<0.05 ;{ }^{*} \mathrm{p}<0.10$

Similarly, the scatter plots of the variables strategic CSR, reactive CSR, and responsible innovation, as shown in Fig. 3 and Fig. 4, indicate that these relationships differ according to the activity sector and the firm size. These results reflect therefore, the possibility of conditional effects of the firm size and the activity sector between CSR strategy and responsible innovation.
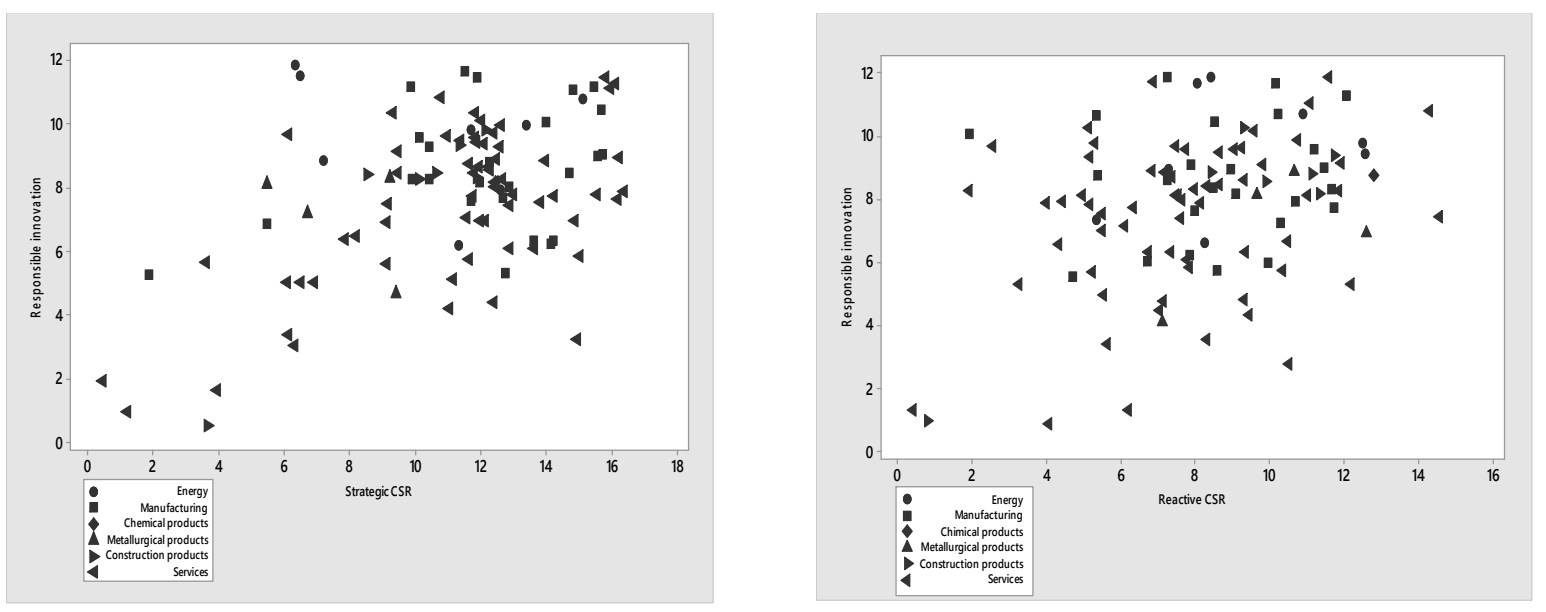

Fig. 3. Scatter plot of the variables reactive CSR, strategic CSR and competitive advantage according to the activity sector 

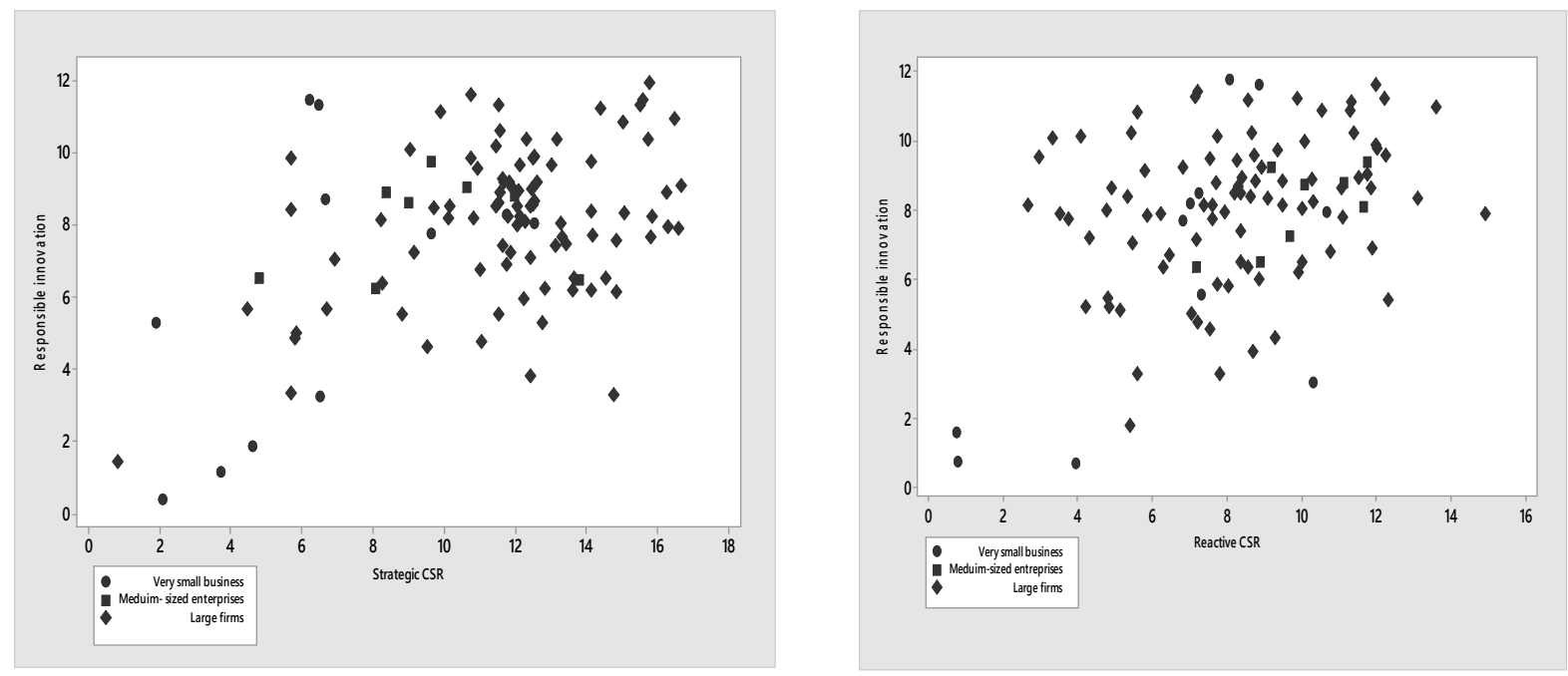

Fig. 4: Scatter plot of the variables reactive CSR, strategic CSR and competitive advantage according to the firm size

As shown in Table 3, the estimations of Models 1 and 3 showed that both strategic and reactive CSR have positive and significant repercussions on responsible innovation $\left(a_{1}=1,008\right.$ and $a_{1}=0.710$, respectively). Our estimates of Model 6 show also that only strategic CSR has a significant and positive effect on competitive advantage $\left(b_{1}=0.653 ; p<0.001\right)$. The effects of the reactive CSR on the competitive advantage illustrated by the model 5 show that they are not significant. These results confirm those of Bocquet et al. (2017) applied to a sample of Luxembourg firms, according to which strategic CSR acts positively on the firm performance, whereas firms that follow responsive and reactive behaviors have negative and counterproductive consequences in terms of economic performance. These results also illustrate that the competitive advantage for a developing country as Saudi Arabia is enhanced by a market pull through the exploitation of opportunities, value creation with social dimensions, and an active and non-responsive attitude towards stakeholders. The results from the estimates of models 1, 3, 5 and 6 reflect overall that the responsible innovation created by the strategic CSR and the reactive CSR differs substantially in nature. Indeed, CSR strategic-based innovations are voluntary, proactive and radical able to significantly boost the competitive advantage of firms. These innovations aim at creating value. In contrast, the CSR reactive-based innovations are responsive, incremental unable to make radical changes capable of strengthening the competitive position of firms. They are imitated by competitors to respond to the instantaneous pressure exerted by the different stakeholders. In other words, reactive CSR is motivated by stakeholders push while, strategic CSR is boosted by a market pull.

The test of the moderating effects of CSR strategy on the responsible innovation by the activity sector and the firm size leads to different results. Our estimates show that the effects of reactive CSR on responsible innovation are moderated by the firm size and not moderated by the activity sector. The interaction term between the reactive CSR and the firm size (size $\mathrm{x}$ rcsr) has a negative and significant effect on the responsible innovation $\left(a_{3}=-0.270, p<0.01\right)$. Given their more flexible organizational form, small firms have closer relationships with employees, which facilitates agreement among them and best meets their requirements. In addition, firm with small size are more subject to consumer pressure as their survival in the market depends on its ability to satisfy its customers (Quairel \& Auberger, 2005). Based on our results of the Models 4 and 6, the effect of strategic CSR on competitive advantage is conditioned by the nature of the sector of activity. Indeed, the term interaction between the sector of activity and the strategic CSR (sector x scsr) has a significant and positive effect on responsible innovation $\left(a_{3}=0.058, \mathrm{p}<0.01\right)$. These results, therefore, indicate that sectoral activity has a different effect on socially responsible innovation depending on the environmental behaviors of the firm and on the growth opportunities that certain sectors offer in terms of innovation capability. Some sectors more than others require more resource efficiency, good waste management and constraining measures to reduce environmental degradation. In addition, the sectors differ according to their technological intensity and therefore, their capacity to innovate. These results would allow us to conclude that the indirect effect of the reactive CSR on competitive advantage through responsible innovation is not moderated by the activity sector but, negatively depending on the firm size. With regard to the activity sector, its conditional effect intervenes only in moderating the effect of strategic CSR on competitive advantage through responsible innovation. 


\section{Table 3}

Conditional effects of firm size and the activity sector of the mediation of the responsible innovation in the relationship between the CSR strategy and the competitive advantage.

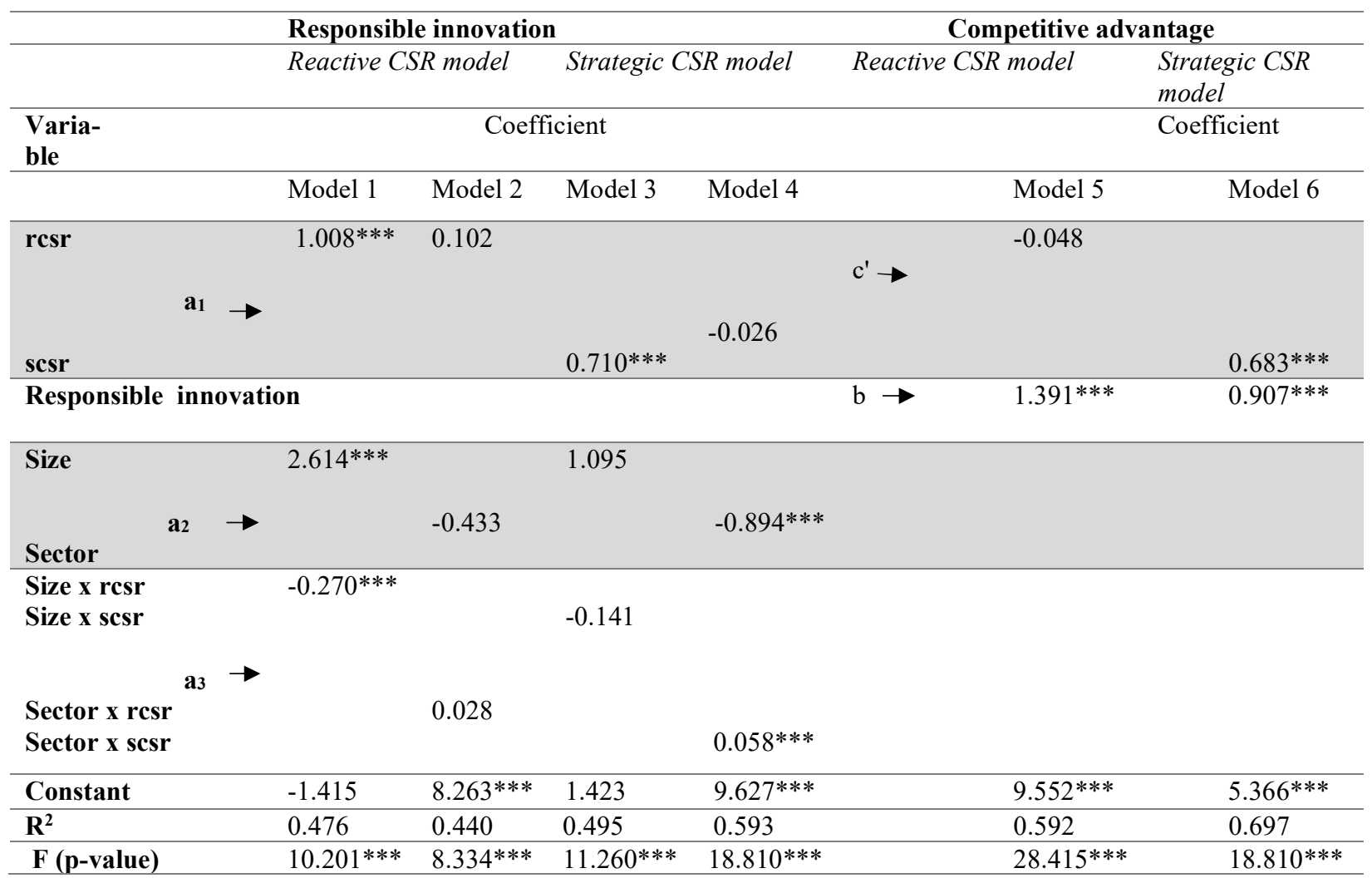

Note: $* * * \mathrm{p}<0.01$.

To confirm the presence of moderated mediation of the variable responsible innovation by the firm size and the activity sector in the relationship between CSR strategy and competitive advantage, we analyze the index of moderated mediation $W$. Indeed, a3 does not quantify the relationship between the moderating effect and the indirect effect but only the moderation of the effect of csr on ri. We followed the approach of Hayes (2015) according to which, if the interval between the lower bound and the upper bound of the confidence interval does not include the value zero, the indirect and conditional effects are valid. Otherwise, these effects are rejected. In what follows, we have based on 95\%, boosted CI for 5000 bootstrap samples. From Table 4, the interval delimited by the upper (95\% ULCI) and lower (95\% LLCI) bounds of the confidence interval for the indirect effects of the firm size and the activity sector does not include the value zero. These results confirm the presence of the indirect effect of reactive CSR on competitive advantage through the firm size and the indirect effect of strategic CSR on competitive advantage through activity sector.

Table 4

Conditional indirect effects of CSR strategy on competitive advantage.

\begin{tabular}{lrrrrr}
\hline & \multicolumn{3}{c}{ Firm size } & \multicolumn{2}{c}{ Activity sector } \\
\hline & Coefficient & $95 \%$ LLCI & 95\%ULCI & Coefficient & $95 \%$ LLCI \\
\hline $\begin{array}{l}\text { Indirect effect of responsible } \\
\text { innovation }\left(\mathrm{a}_{1} \mathrm{x} \text { b) }\right.\end{array}$ & 1.402 & 0.121 & 0.753 & 0.289 & 0.113 \\
$\begin{array}{l}\text { Index of moderated mediation } \\
\text { (W) }\end{array}$ & -0.376 & -0.472 & -0.123 & 0.053 & 0.546 \\
\end{tabular}

With a bootstrap confidence interval of $95 \%$ for the index of moderated mediation (W), it can be seen from the table 4 that this index different from zero for the two variables, activity sector and firm size. The slope of this function $\mathrm{W}$ is between 0.472 and -0.123 for the variable firm size and between 0.013 and 0.103 for the variable activity sector. Since this confidence interval does not include zero and the upper bound is negative for firm size and positive for sector activity, it can be concluded that the indirect effect of CSR strategy on competitive advantage through responsible innovation is negatively conditioned by the firm size and positively moderated by the activity sector. These results partially validate our hypothesis H.2 and H.3, and 
totally our hypotheses $\mathrm{H}_{2 \mathrm{a}}$ and $\mathrm{H}_{3 \mathrm{~b}}$. In the light of these results, our final statistical moderated mediation model of responsible innovation between CSR strategy and competitive advantage is schematized by Fig. 5 as follow:

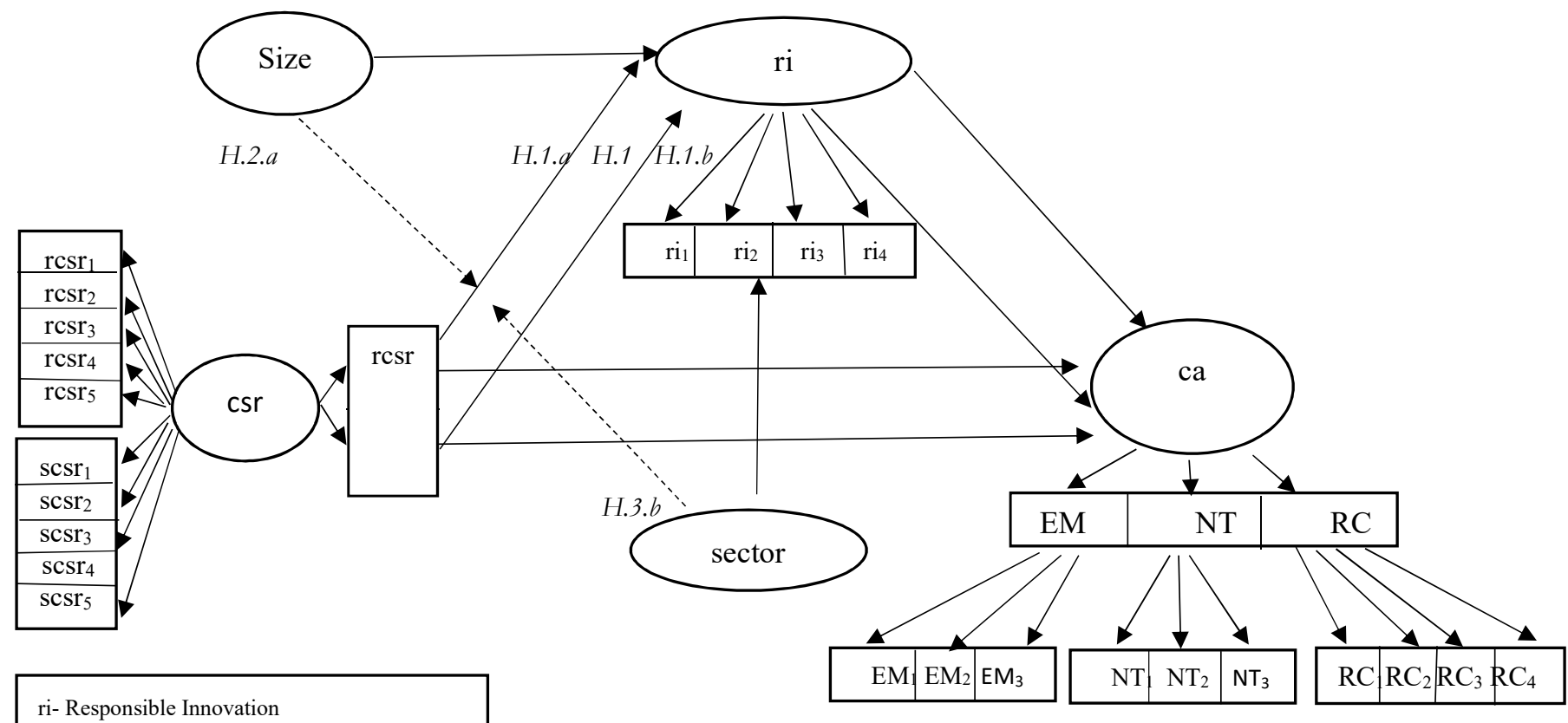

csr- Corporate social responsibility

rcsr- Reactive corporate social responsibility

scsr- Strategic corporate social responsibility

ca- Competitive advantage

EM- Exploitation of market opportunities

NT- Neutralization of threats

RC- Reducing of total cost

Fig. 5. Degree of relationship between CSR, responsible innovation and competitive advantage.

\section{Conclusion and implications}

This study has examined whether the competitive advantage for developing countries such as Saudi Arabia is determined by a strategic or reactive vision of the CSR policy. In addition, we analyzed the moderated-mediation role of responsible innovation and its conditional indirect effects in the relationship between CSR strategy and competitive advantage. Indeed, while the previous literature focused on a mediation model of CSR-based competitiveness, we provided a moderated mediation model of CSR-based competitiveness. In this practical model, we have presented the channels through which the CSR affects the competitive advantage by incorporating the strategic or reactive nature of the CSR, the firm size, and the sector of activity. This approach has allowed us to enrich the literature of resource-based view that has focused mainly for the mediation analysis of the CSR-based competitiveness and it was essentially limited to the role of the reputational capital without paying more attention to the role of innovation. In addition, our analysis focused on the CSR policy and its conditional indirect effects on competitive advantage in the case of a developing country, while the majority of previous research focused on the developed countries. These conditional indirect effects of CSR on competitive advantage were analyzed by distinguishing between the role of the firm size and the sector of activity as moderating variables.

Our results show that responsible innovation is a key element of the sustainable business model since it determines the success of CSR strategy in boosting the competitive advantage of firms. In this model, the mediation of responsible innovation is moderated differently by the firm size and the activity sector, and it is dependent on the choice between strategic or reactive CSR strategy. Within this context, we also find that the indirect effects of the CSR strategy on competitive advantage are moderated by the firm size in the case of reactive CSR, whereas by the activity sector in case of strategic CSR._The results provided by this paper have some implications for the policy that needs to be adopted by the manager. Indeed, stakeholder push in order to create socially responsible innovations seems stronger in smaller firms than larger firms. In addition, the characteristics of the activity sector in terms of its technological intensity and environmental behavior are decisive for the strategic CSR to strengthen the firm competitive position. In other words, the moderated-mediation of responsible innovation by the activity sector in the relationship between strategic CSR and competitive advantage is justified by a market pull for socially responsible goods and market growth opportunities. On one side, small companies create responsible innovations, according to a reactive vision of CSR. This illustrates the importance for managers of these companies to include the opinions of employees and the requirements of consumers in their decision-making. Indeed, in small companies the links between 
employees and managers are more formal compared to the larger companies and can contribute to the design of responsible innovations. On the other side, the ability to produce responsible innovations, according to a strategic vision of CSR depends on the sector in question. For this purpose, some sectors are more polluting and more technology intensive than others. In these sectors, it is up to the managers, to take into consideration the following actions: i) The sensitization of stakeholders on products with CSR value; ii) The management of the relationships between stakeholders; iii) The voluntary participation of the firm in social actions; (iv) The value creation through product / service innovation for social purposes; and v) The ability to anticipate social changes that present market opportunities._Besides to the contributions and implications provided above, we are cautious to note that our analysis and results suffer from some limitations that should be pointed out: First, our findings cannot be generalized within a broader framework of developing countries. The Saudi case is insufficient as a predictable model in terms of CSR policy, which requires a wider panel of developing countries to provide concrete recommendations. Second, the moderated-mediation analysis of CSR-based competitiveness concerns only the first stage of the moderated mediation between the CSR strategy and responsible innovation. Therefore, an in-depth analysis of others moderating variables in the second stage of moderated mediation between responsible innovation and competitive advantage seems an important future research track.

\section{Acknowledgments}

This study has been conducted by a fund granted from the Deanship of Scientific Research in Qassim University, Saudi Arabia.

\section{References}

Adams, R., Sally J., John B., David D., \& Patrick O. (2016). Sustainability-oriented innovation: A systematic review. International Journal of Management Reviews, 18(2), 180-205.

Aggeri, F., \& Godard, O. (2006). Les entreprises et le développement durable. Entreprises et histoire, 45(4), 6-19.

Al-Shuaibi, K. (2016), A Structural Equation Model of CSR and Performance: Mediation by Innovation and Productivity, Journal of Management and Sustainability, 6(2), 139-153

Anser, M. K., Zhang, Z., \& Kanwal, L. (2018), Moderating effect of innovation on corporate social responsibility and firm performance in realm of sustainable development. Corporate Social Responsibility and Environmental Management, 25(5), 799-806.

Barnett, M. L., \& Solomon, R. M. (2006). Beyond dichotomy: The curvilinear relationship between social responsibility and financial performance. Strategic Management Journal, 27, 1101-1122.

Bocquet, R., \& Mothe, C. (2011). Exploring the relationship between CSR and innovation: A comparison between small and largesized French companies, 80, 101-119.

Bénabou, R., \& Tirole, J. (2010). Individual and corporate social responsibility. Economica, 77(305), 1-19.

Berger-Douce, S. (2007). Les stratégies d'engagement sociétal des entrepreneurs. Revue de l'Entrepreneuriat, 6(1), 53-71.

Bocken, N. M. P., Short, S. W., Rana, P., \& Evans, S.(2014). A literature and practice review to develop sustainable business model archetypes, Journal of cleaner production, 65, 42-56.

Bocquet, R., \& Mothe, C. (2013). Profil des entreprises en matière de RSE et innovation technologique. Management Avenir, (8), 132-151.

Bocquet, R., Le Bas, C., Mothe, C., \& Poussing, N. (2013), Are firms with different CSR profiles equally innovative? Empirical analysis with survey data. European Management Journal, 31(6), 642-654.

Bocquet R., Le Bas, C., Mothe C., \& Poussing N. (2017). CSR, innovation, and firm performance in sluggish growth contexts: A firm-level empirical analysis. Journal of Business Ethics, 146(1), 241-254.

Boirel, O., Heras Saizarbitoria, I., \& Testa, F. (2017). SA8000 as CSR-Washing? The role of the stakeholder pressures. Corporate Social Responsibility and Environmental Management, 24(1), 57-70.

Bonneveux, E., \& Saulquin, J. Y. (2009). L'appropriation de la RSE par les dirigeants de PME. Le réseau comme vecteur de l'apprentissage managérial. Management Avenir, 23(3), 170-186.

Boons, F., \& Lüdeke-Freund, F. (2013). Business models for sustainable innovation: state-of-the-art and steps towards a research agenda, Journal of Cleaner Production, 45, 9-19.

Brammer, S., Pavelin, S., \& Porter, L. A. (2009). Corporate charitable giving, multinational companies and countries of concern. Journal of Management Studies, 46(4), 575-596.

Brion, S., Favre-Bonté, V., \& Mothe, C.(2008). Quelles formes d'ambidextrie pour combiner innovations d'exploitation et d'exploration? Management International, 12(3), 29-44.

Brown, W. O., Hellanda, E., \& Smith, J. K. (2006). Corporate philanthropic practices. Journal of Corporate Finance, 12(5), 855-877.

Burke, L., \& Logsdon, J. M. (1996). How corporate social responsibility pays off. Long Range Planning, 29(4), 495-502.

Capron, M., Quairel-Lanoizelee, F. (2007). La responsabilité sociale d'entreprise, La Découverte, Paris.

Callan, S. J., \& Thomas, J. M. (2009). Corporate financial performance and corporate social performance: an update and reinvestigation. Corporate Social Responsibility and Environmental Management, 16(2), 61-78.

Chen, K., Chen, Z., \& Wei, K. (2009), Legal protection of investors, corporate governance, and the cost of equity capital. Journal of Corporate Finance, 15, 273-289 
De Marchi, V. (2012), Environmental innovation and R\&D cooperation: Empirical evidence from Spanish manufacturing firms. Research Policy, 41(3), 614-623.

Depret, M.-H., \& Hamdouch, A. (2009). Clusters, réseaux d'innovation et dynamiques de proximité dans les secteurs HighTech : Une revue critique de la littérature récente. Revue d"Economie Industrielle, 128, 21-52.

Dorobantu, S., Kaul, A., \& Zelner, B.(2017). Nonmarket strategy research through the lens of new institutional economics: An integrative review and future directions. Strategic Management Journal, 38(1), 114-140.

Edwards, J. R. ,\& Lambert, L. S.(2007). Methods for integrating moderation and mediation: A general analytical framework using moderated path analysis, Psychological Methods, 12, 1-22.

Fairchild, A. J., \& MacKinnon, D. P. (2009), A general model for testing mediation and moderation effects. Prevention Science, 10, 87-99.

Gallego-Alvarez, I., Prado-Lorenzo J. M., \& Garcia-Sanchez, I-M. (2011), Corporate social responsibility and innovation: A resource-based theory. Management Decision, 49(10), 1709-1727.

Geels, F. W. (2014). Regime resistance against low-carbon transitions: introducing politics and power into the multi-level perspective. Theory, Culture \& Society, 31(5), 21-40.

Geels, F. W., \& Penna, C. C. (2015). Societal problems and industry reorientation: Elaborating the Dialectic Issue LifeCycle (DILC) model and a case study of car safety in the USA (1900-1995). Research Policy, 44(1), 67-82.

Hair, J., Anderson, R., Tatham, R.L., \& Black, W.C. (1998). Multivariate data analysis. (5th ed.), NJ: Upper Saddle River, Prentice-Hall.

Halme, M., \& Korpela, M. (2014). Responsible innovation toward sustainable development in small and medium-sized enterprises: A resource perspective. Business Strategy and the Environment, 23(8), 547-566.

Hamel, G., \& Prahalad, C.K. (1990). The core competence of the corporation. Harvard Business Review, 68(3), 79-92.

Hart, S.-L. (1995). A natural-resource-based view of the firm. Academy of Management Review, 20(4), 986-1014.

Hayes, A. (2015). An index and test of linear moderated mediation. Multivariate Behavioral Research, 50, 1-22.

Henriques, I., \& Sadorsky, P. (1999). The relationship between environmental commitment and managerial perceptions of stakeholder importance. Academy of Management Journal, 42, 87-99.

Hou, T. C. (2019). The relationship between corporate social responsibility and sustainable financial performance: firm-level evidence from Taiwan, Corporate Social Responsibility and Environmental Management, 26(1), 19-28.

Hull, C. E., \& Rothenberg, S. (2008), Firm performance: The interactions of corporate social performance with innovation and industry differentiation. Strategic Management Journal, 29(7), 781-89.

Hur, W., Kim, H., \& Woo, J. (2014). How CSR leads to corporate brand equity: Mediating mechanisms of corporate brand credibility and reputation. Journal of Business Ethics, 125(1), 75-86.

Husted, B.-W., \& Allen, D.-B. (2007). Corporate social strategy in multinational enterprises: Antecedents and value creation. Journal of Business Ethics, 74, 34-361.

Iatridis, K. and Kesidou, E. (2018). What drives substantive versus symbolic implementation of ISO 14001 in a time of economic crisis? Insights from Greek manufacturing companies. Journal of Business Ethics, 148(4), 859-877.

Jamali, D., \& Karam C. (2018). Corporate social responsibility in developing countries as an emerging field of study. International Journal of Management reviews, 20(1), 32-61.

Klewitz, J., \& Hansen, E. G. (2014). Sustainability-oriented innovation of SMEs: a systematic review. Journal of cleaner production, 65, 57-75.

Lai, C. S., Chiu, C. J., Yang, C. F., \& Pai, D. C. (2010). The effects of corporate social responsibility on brand performance: The mediating effect of industrial brand equity and corporate reputation. Journal of business ethics, 95(3), 457-469.

Ldemudia, U. (2011). Corporate social responsibility and developing countries: moving the critical CSR research agenda in Africa forward. Progress in development studies, 11(1), 1-18.

Lutz, S., Lyon, T.P., \& Maxwell, J.W. (2000). Quality leadership when regulatory standards are forthcoming. The Journal of Industrial Economics, 48(3), 331-348

Lyon, T. P., \& Maxwell, J.W. (2008), Corporate social responsibility and the environment: A theoretical perspective. Review of Environmental Economics and Policy, 1, 1-22.

MacGregor, S.P., Spinach, X., \& Fontrodona, J. (2007). Social innovation: Using design to generate business value through corporate social responsibility. IESE Business School, University of Gerona, Spain.

Maden, C., Arıkan, E., Telci, E. E., \& Kantur, D. (2012). Linking corporate social responsibility to corporate reputation: a study on understanding behavioral consequences. Procedia-Social and Behavioral Sciences, 58, 655-664.

Madsen, P. M. and Rodgers, Z. (2015). Looking good by doing good: The antecedents and consequences of stakeholder attention to corporate disaster relief. Strategic Management Journal, 36(5), 776-794.

Margolis, J.D., \& Walsh, J.P. (2001). People and profits: The search for a link between a company's social and financial performance. Lawrence Erlbaum Associates: Mahwah, NJ.

Marin, L., Matin, P. J., \& Rubio, A. (2017). Doing good and different! The mediation rffect of innovation and investment on the influence of CSR on competitiveness. Corporate Social Responsibility and Environmental Management, 24, $159-171$.

Martínez-Ferrero, J., \& Frías-Aceituno, J. V. (2015). Relationship between sustainable development and financial performance: international empirical research. Business Strategy and the Environment, 24(1), 20-39.

Moon, J., \& Shen X. (2010). CSR in China research: Salience, focus and nature. Journal of Business Ethics, 94(4), 613-629.

Morgan-Lopez, A., \& MacKinnon, D. P. (2006). Demonstration and evaluation of a method for assessing mediated moderation. Behavior Research Methods, 38, 77-89. 
Nidumolu, R., Prahalad, C.K., \& Rangaswami, M.R. (2009). Why sustainability is now the key driver of innovation. Harvard business review, 87(9), 56-64.

Nunnally, J. C. (1978). Psychometric theory (2nd ed.). New York, NY: McGraw-Hill.

Orlitzky, M., Schmidt, F. L., \& Rynes, S.L.(2003). Corporate social and financial Performance: A meta analysis. Organization Studies, 24(3), 403-441.

Özdamar, K. (2002), Paket Programlar ile İstatistik Veri Analizi, Eskişehir: Kaan Kitapevi, 661-673.

Paradas, A. (2007). Le dirigeant comme levier de la RSE en TPE: approche exploratoire basée sur l'utilisation de récits et d'une cartographie cognitive. Revue internationale PME Économie et gestion de la petite et moyenne entreprise, 20(3-4), 43-67.

Pomering, A., \& Dolnicar, S. (2009). Assessing the prerequisite of successful CSR implementation: are consumers aware of CSR initiatives?. Journal of Business Ethics, 85(2), 285-301.

Porter, M.E. \& Kramer, M.R. (2006). Strategy \& society: The link between competitive advantage and corporate social responsibility. Harvard business review, 84(12), 78-92.

Porter, M.E., \& van der Linde, C. (1995). Toward a new conception of the environment-competitiveness relationship. Journal of Economic Perspectives, 9(4), 97-118.

Preacher, K. J., Rucker, D. D., \& Hayes, A. F. (2007), Assessing moderated mediation hypotheses: Theory, methods, and prescriptions. Multivariate Behavioral Research, 42, 185-227.

Rogers, E.M. (1962). Diffusion of innovations, The Free Press Of Glencoe, New York.

Saeed, M. M., \& Arshad, F. (2012), Corporate social responsibility as a source of competitive advantage: The mediating role of social capital and reputational capital. Journal of Database Marketing \& Customer Strategy Management 19(4).

Shrivastava, P. (1995). Environmental Technologies and Competitive Advantage. Strategic Management Journal, 16(special issue), 183-200.

Siegel, D., \& Vitaliano, D. (2007). An empirical analysis of the strategic use of corporate social responsibility. Journal of Economic Management and Strategy, 16(3), 773-792.

Sigalas, Ch., Economou, V.P., Georgopoulos, N.B. (2013). Developing a measure of competitive advantage. Journal of Strategy and Management, 6(4), 320-342.

Simpson, W.G and Kohers, T. (2002), The Link Between Corporate Social and Financial Performance: Evidence from the Banking Industry. Journal of Business Ethics, 35(2), 97-109.

Stilgoe, J., Owen, R., Macnaghten, P. (2013). Developing a framework for responsible innovation. Research Policy, 42, 15681580

Su, W., Peng, M. W., Tan, W., \& Cheung, Y. L. (2016). The signaling effect of corporate social responsibility in emerging economies. Journal of business Ethics, 134(3), 479-491.

Teece, D. J., Pisano, G., \& Shuen, A. (1997). Dynamic capabilities and strategic management. Strategic Management Journal, 18(7), 509-533.

Van den Berghe, L., \& Louche, C. (2005). The link between corporate governance and corporate social responsibility In insurance. The Geneva Papers on Risk and Insurance-Issues and Practice, 30(3), 425- 442.

Vilanova, M., Lozano, J. M., \& Arenas, D. (2009). Exploring the nature of the relationship between CSR and competitiveness. Journal of business Ethics, 87(1), 57-69.

Wagner, M. (2010). The role of corporate sustainability performance for economic performance: A firm-level analysis of moderation effects. Ecological Economics 69(7), 1553-1560.

Wernerfelt, B. (1984). A resource based view of the firm. Strategic Management Journal, 5, 171- 180.

Wüstenhagen, R., \& Boehnke, J. (2008), Business models for sustainable energy, in: Tukker, A.; Charter, M.; Vezzoli, C.; Sto, E.\& Andersen, M.M.(eds.), System Innovation for Sustainability. Perspectives on Radical Changes to Sustainable Consumption and Production, Sheffield: Greenleaf Publishing Ltd., 85-94.

Zhao, Z., Meng, F. He, Y. and Gu Z. (2019). The influence of corporate social responsibility on competitive advantage with multiple mediations from social capital and dynamic capabilities. Sustainability, 11(1), 218.

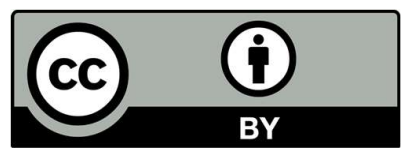

(C) 2020 by the authors; licensee Growing Science, Canada. This is an open access article distributed under the terms and conditions of the Creative Commons Attribution (CC-BY) license (http://creativecommons.org/licenses/by/4.0/). 